\title{
A Nike e o Brasil imaginado: a produção do comercial Mandingas para a Copa do Mundo de 2010
}

\section{Fabio Eloi de Oliveira}

Universidade Metodista de São Paulo, Escola de Comunicação e Humanidades, São Bernardo do Campo, SP, Brasil

ORCID: https://orcid.org/0000-0002-1157-7564

\section{Dimas A. Künsch}

Universidade Metodista de São Paulo, Programa de Pós-Graduação em Comunicação Social, São Bernardo do Campo, SP, Brasil

ORCID: https://orcid.org/0000-0001-5621-898X

\section{Resumo}

Os quatro comerciais de lançamento das campanhas da Nike para as Copas do Mundo de 2006 a 2018, e particularmente o mais extenso deles, Mandingas, para a Copa de 2010, constituem o objeto deste ensaio, com foco no Brasil imaginado do qual essa produção publicitária deriva. Pretende-se mostrar como a maior empresa de artigos esportivos do mundo interage com o imaginário social, num duplo sentido, tanto da busca de seus referenciais nesse imaginário como, ao mesmo tempo, de alimento e reprodução dessas construções simbólicas por meio dos filmes produzidos. Metodologicamente, a pesquisa toma por base a Hermenêutica de Profundidade, como formulada por John B. Thompson, com o suporte da análise de conteúdo e à luz mais ampla da compreensão como método. O texto espera promover a compreensão a respeito de como a publicidade pode atuar como formadora de vínculos entre a marca e o seu público, o que significa, no caso específico, com a própria nação brasileira.

\section{Palavras-chave}

Comunicação; Publicidade; Imaginário social; Compreensão; Nike 


\section{Introdução}

Este texto, em estilo de ensaio, representa não mais que uma pequena porção de uma pesquisa maior, com o título Nike, futebol e propaganda: a produção publicitária no Brasil em tempo de Copa do Mundo, tese de doutoramento do primeiro autor deste trabalho (OLIVEIRA, 2020), orientada pelo segundo. 0 tema se reveste de relevância social, já a partir de seus significados econômico-financeiros, bem como políticos e culturais. Semelhante relevância entendemos que possa ser atribuída a esse estudo também em sua relação com a Comunicação, esse campo de conhecimento em constante e cada vez mais rápidos movimentos nos tempos que correm, no qual tanto o marketing quanto a publicidade se situam.

Tentamos, nessa conversa-ensaio, fugir em primeiro lugar ao risco de nos tornarmos vítimas do jogo fácil das generalizações no tratamento de temas relativos a grandes corporações, como a Nike, no seio do capitalismo. Entendemos ser necessário, primeiro, abrirmos a mente para ousar compreender os fenômenos sociais, o quanto possível, como eles em primeiro lugar se mostram (phainomenon, em grego). Mostrar, mais que demonstrar, pode ser considerado um objetivo a ser perseguido. Essa intenção, aliás, se não esgota as possibilidades de uma aproximação compreensiva ao tema, traduz uma atitude intelectual em consonância com os propósitos do ensaio como gênero compreensivo de escrita.

Parar nesse ponto, porém, está longe de ser desejável. A partir dessa primeira aproximação, esforçamo-nos para responder à pergunta sobre como a maior empresa de artigos esportivos do mundo interage com o imaginário social brasileiro na produção dos comerciais para as Copas do Mundo de Futebol de 2006 (JOGA BONITO), na Alemanha; 2010 (MANDINGAS), na África do Sul; 2014 (MOSTRA SEU JOGO), no Brasil; e 2018 (BRASILEIRAGEM), na Rússia. O foco, como aparece já no título, recai quase exclusivamente sobre um desses comerciais, Mandingas, o mais extenso deles, veiculado em 2010.

O objetivo geral é compreender como futebol, religião, condição social, música, negritude e outros elementos menos salientes vão se misturando para tecer um arcabouço de sentimentos e afetos que acionam uma leitura, entre outras possíveis, de brasilidade. Essa leitura, como deve se tornar claro, termina por reforçar aquilo que se entende como 
constitutivo de nossa identidade nacional. Ao mesmo tempo, perguntamo-nos sobre os modos como isso colabora para a constituição da estratégia mercadológica local da Nike.

Três são as partes em que se estrutura este texto. A primeira trata de uma mudança importante - embora esteja longe de ser absoluta - na autocompreensão das empresas em sua relação com os públicos que elas tentam atingir e atender, e que diz respeito a uma passagem do mundo da produção para o do consumo, do produto para sua imagem. A segunda parte traz alguns apontamentos sobre a abordagem teórico-metodológica. Por fim, a terceira aplica o modelo interpretativo-compreensivo, esboçado na segunda parte, ao comercial Mandingas (2010). Desde este momento é preciso sublinhar que essa aplicação é em muitos pontos e sentidos apenas indicada, mais do que explorada em todas as suas possibilidades, o que fugiria ao escopo deste ensaio e do volume possível de texto que as normas editoriais da revista têm como justas.

\section{Imagem da empresa e a marca como estrela}

A partir principalmente dos anos 1980, as preocupações mais importantes das grandes empresas deixaram cada vez mais de ser endereçadas quase que exclusivamente à fabricação de produtos para o consumo, para se concentrarem paulatinamente na construção da imagem de si mesmas, por meio da criação de uma marca e do investimento maciço em marketing.

Essa mudança de foco corresponde em muitos aspectos à passagem da sociedade sólida para a líquido-moderna, ou, ainda, de produtores para a de consumidores, na visão de Zygmunt Bauman (2001). Nesse admirável mundo da produção e do consumo, o significado simbólico de um produto ou serviço tende a assumir uma importância que, no mínimo, compete com sua expressão material. Ao dizermos, linhas atrás, que essa mudança não pode ser encarada como absoluta, pretendemos chamar a atenção para o fato de que seria um absurdo negar aos produtos e ao seu consumo a sua sempre muito importante materialidade, e até mesmo primazia, dependendo da perspectiva sob a qual são contemplados. Com efeito, a ordo idearum, que a análise aqui embutida sugere, não tem por que ser confundida com a ordo rerum, com as suas complexidades.

Feita essa ressalva, podemos afirmar que a fórmula de atribuir uma dose cada vez mais significativa de prestígio à marca não possui nada de mágico, especialmente na relação 
com o objeto que nos ocupa: foi descoberta e aplicada pela Nike - a $16^{\mathrm{a}}$ marca mais valiosa do mundo e a primeira entre as marcas esportivas, segundo dados de 2019 - desde praticamente as suas origens, no início dos anos 1960. 0 resultado é que hoje a empresa representa, mais que qualquer grande corporação do mundo, acima de tudo, uma marca. Para todos os efeitos, trata-se, no caso, de um produto típico do universo plástico e sem contornos definidos da imagi(n)ação. Mas com resultados comerciais incontestáveis.

Kevin Roberts (2004) refina a análise para sublinhar como, nesse contexto amplo e complexo de mudanças, as grandes corporações trabalham hoje com muito mais afinco na geração de fidelidade por meio de conexões emocionais com os seus consumidores. Vendem-se marcas e estilos de vida, mais que apenas produtos - e essa ideia conversa magistralmente com a de "modernidade líquida" (BAUMAN, 2001), em que os produtos, sólidos, adquirem relativamente importância menor que o seu consumo e o que esses produtos podem significar.

A Nike patrocina a Seleção Brasileira de Futebol desde 1995. Nas peças publicitárias produzidas pela empresa e veiculadas no Brasil como parte de suas campanhas em períodos de Copas do Mundo, observamos que essa estratégia se efetiva na procura por aquilo que, nunca sem problemas de ordem teórico-analítica, poderíamos chamar de identidade nacional, ainda que imaginada. Merece destaque, no caso das peças publicitárias em questão, e especialmente em Mandingas (2010), o tema da religiosidade e do sincretismo religioso.

Essa estratégia de aproximação à (imaginada) brasilidade se manifesta, também, em vários momentos por meio de uma narrativa que adere ao modelo mitológico da jornada do herói, como proposta por Joseph Campbell, em O herói de mil faces (CAMPBELL, 1989). 0 herói mitológico emerge do mundo comum da escassez e da miséria e se alça ao Olimpo da fama e da glória, com o beneplácito de forças divinas. 0 modelo se adequa bem a um tipo de sociedade e de país, como o Brasil, com suas assimetrias sociais históricas, onde o binômio pobre-preto, como apontamos adiante, sempre gritou alto no mundo do futebol.

Nesse mundo mítico-imaginário em que humano e divino se tocam, nada melhor do que contar com a força incomensurável de Niké, a deusa grega da vitória. As associações entre a Nike e o esporte com suas celebridades representam a própria essência, a alma viva da empresa, que construiu o seu branding a partir de conexões entre a marca e 
personalidades famosas. Ora, esporte, futebol e Copa do Mundo acionam, como bem se sabe, grandes e profundas emoções. Movimentam esse território do humano, em extensa medida inconsciente, onde residem nossos sonhos arquetípicos e se engendram os nossos mitos (JUNG, 2001, 2008) pessoais e coletivos. Justamente esse campo acaba por ser mobilizado com volúpia pelas grandes empresas para nele ser executado o que Roberts (2004) indica como o grosso dos investimentos em marketing.

0 fato amplamente reconhecido de a Nike consistir antes de tudo numa marca mereceu já nos anos 1990 da jornalista e autora canadense Naomi Klein a denominação de “corporação oca” (1999, p. 14), que ela assim descreve: "Fabricantes de hoje não mais fazem os produtos e os distribuem, mas em vez disso compram produtos e lhes dão sua marca". Trata-se de empresas que não existem para além dos seus escritórios de representação e de marketing, terceirizando a sua produção por diversas outras fábricas ao redor do mundo, sempre em busca do menor custo. Crítica mordaz desse jogo no período, Klein (1999, p. 32) considerava que, "embora nem sempre seja a intenção original, o efeito do branding avançado é empurrar a cultura que o hospeda para o fundo do palco e fazer da marca a estrela. Isso não é patrocinar cultura, é ser a cultura". E isso de novo vai ao encontro do pensamento de Kevin Roberts (2004), uma vez que vínculos emocionais de uma sociedade se dão, também, por meio das suas identidades culturais.

\section{Apontamentos teórico-metodológicos}

Se, como observa Néstor García Canclini (2000), o consumo, em suas complexas relações materiais e imaginárias, nos faz pensar, e bastante, isso nos parece assumir uma expressão ainda mais verdadeira durante um evento da dimensão de uma Copa do Mundo de futebol. Nesse momento, a cada quatro anos, é trazido fortemente para o palco da vida cotidiana, com o poder do dinheiro, da mídia corporativa e de outros tantos interesses, o sentimento geral de brasilidade, por razões conhecidas e também desconhecidas, reais, no sentido físico do termo, e imaginárias, no sentido psíquico e espiritual.

Essas dinâmicas embaralham os territórios da tragédia e da comédia humanas, por certo distintas de país para país; se afirmam, se produzem e reproduzem, de muitos modos e às vezes tacitamente, para além ou acima de assimetrias sociais e de questões como as de gênero, de classes, ideologias etc. Toda essa arquitetura de ações mercadológicas, midiáticas 
e também políticas, que uma coisa sempre anda misturada com a outra, deixa explícito como o futebol consegue criar interação entre públicos distintos que, no cotidiano de suas existências, encontram-se muitas e tristes vezes separados por abismos colossais, e de toda ordem.

Pode-se, no entanto, ao mesmo tempo e compreensivamente argumentar que os múltiplos lados mercantil-ideológicos que promovem e atravessam o mundo dos sentidos gerados por uma grande empresa como a Nike em época de Copa do Mundo reservam possibilidades de análise que se situam acima de visões reducionistas, fundadas em dualismos do tipo bem e mal, certo e errado, verdadeiro e falso. Não proíbem nem inviabilizam o entendimento de que há no esporte, como em outros fenômenos sociais e culturais de grande alcance e expressividade, muito mais sentidos sendo produzidos e vivenciados do que imagina a nossa vã filosofia. Não por último, como exemplo, um merecido crédito é necessário ser dado ao lugar do lúdico na esfera constitutiva do humano ser. O homo ludens (HUIZINGA, 2009) sonha, brinca e se diverte com tanta coisa e, assim agindo, se constitui como humano, junto e para além de suas identidades diversas como sapiens, faber etc., fazendo largo uso do seu poder de simbolizar o mundo e a vida.

Assim, para além da muito reconhecida e acionada crítica guydebordiana ao espetáculo, em seu sentido mercantil ou mercadológico (DEBORD, 2007), pode ser lícito afirmar igualmente o direito humano e social ao próprio espetáculo. Em resumo, dito aqui de forma simples, é possível gostar ou não do futebol como de qualquer outro esporte, qualquer que seja o posicionamento, crítico ou alienado, do próprio cidadão frente às assimetrias e anomalias diversas que constituem e atravessam o tecido social e as mazelas todas que podem envolver grandes corporações como a Nike. Uma visão multiperspectívica dos fenômenos, sugerida fortemente por Nietzsche em sua percepção sobre o ato, que tudo abarca, de interpretar (SOUSA, 2019), e aplicada de forma explícita por Douglas Kellner (2001) em seus estudos sobre cultura da mídia, traz a conversa, encetada por este ensaio, para o tema de um pensamento, ora método, compreensivo, como ainda teremos a oportunidade de salientar. 
Figura 1 - Cena inicial de "Mandingas" e o tema da religiosidade como categoria de análise

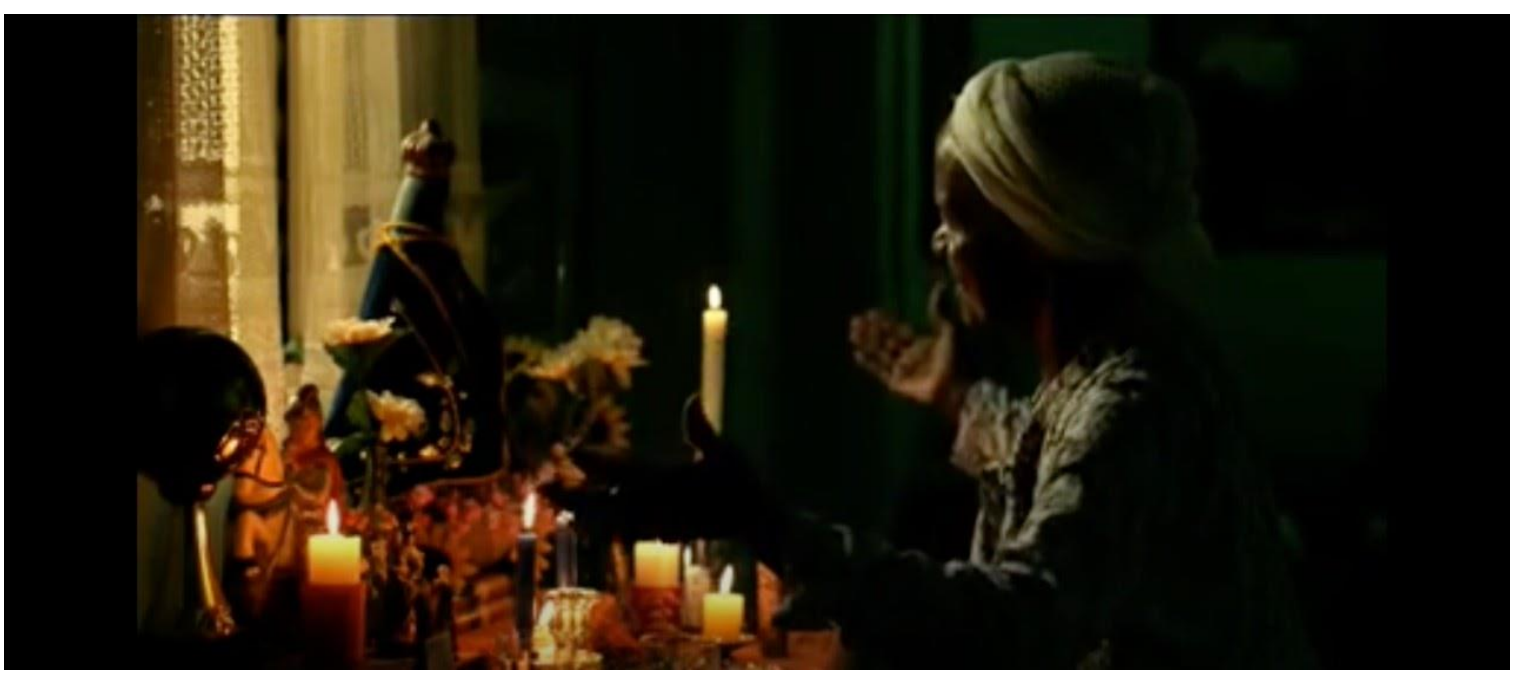

Fonte: Mandinga (2010, [Frame 1"14"]).

Para uma adequada contextualização das relações entre imaginário e identidade nacional, avançamos pelo caminho - o meta+hodós, grego = método - de uma interpretação sobre como o futebol integra o entendimento de identidade cultural no Brasil, no jogo atual de forças entre a secularização do esporte, com seus negócios bilionários e seu glamour, e o caráter ritualístico, presente, principalmente, nas relações entre jogadores de futebol e torcedores (HELAL, 1990) - um aspecto, este último, que a bilionária Nike sabe usar muito profissionalmente a seu favor para os propósitos mercadológicos que cultiva a relação com seus públicos.

Neste sentido, os rituais, sobretudo os que envolvem os torcedores, se aproximam de celebrações religiosas, como bem indica Anatol Rosenfeld (1993), em Negro, macumba e futebol. Uma e outra obras se juntam a $O$ negro no futebol brasileiro, do jornalista Mário Filho (2003), para indicar como a negritude e o sincretismo religioso são os principais pilares da construção de uma identidade em torno do futebol, porque o futebol foi (visto/imaginado como), desde a sua implantação no Brasil, uma ferramenta de ascensão social para os negros - daí a sua provável ligação com as religiões de matriz africana que permeiam as narrativas em torno desse esporte.

E a religião ocupa de fato papel de destaque no desenvolvimento deste estudo, sob a ótica da Matriz Religiosa Brasileira, a MRB, desenvolvida por Magali Cunha (2007), que mostra de que modo o brasileiro, na visão dessa autora, entende e se conecta com o divino, o 
sobrenatural, para além e muitas vezes a despeito dos jogos de sentidos institucionais e hierárquicos. Assim, quase que por consequência, podemos associar a ideia de que o futebol é uma oportunidade de vencer na vida, com apoio de "entidades superiores", com a representação da jornada do herói de Joseph Campbell (1989), como postulado, como mais um elemento que se desdobra por todo o trabalho: a compreensão de que a jornada do herói estabelece um paralelo entre os astros da seleção brasileira de futebol e o cidadão comum.

É a partir dessas construções simbólicas que estruturam as narrativas das peças publicitárias que elencamos como recortes possíveis de investigação, no escopo da análise de conteúdo (BARDIN, 2011), as categorias das Expressões Religiosas, da Jornada do Herói e do próprio construto da Identidade Nacional, tendo em conta dois aspectos que merecem ser mencionados: o primeiro é que a Religiosidade, sendo considerada um componente da identidade nacional, recebe um tratamento à parte, por sua importância nos comerciais escolhidos. Já no item Identidade Nacional nos concentramos em elementos que, ao lado dos símbolos clássicos (como bandeira, hino, camisa da Seleção etc.), possuem um caráter fortemente imaginário, de um modo diferente na cultura movente do cotidiano, como a ginga, o samba, a malandragem, o jeitinho, a favela, o espírito resiliente e, acima de tudo, o suposto jeito brasileiro de jogar futebol - que carregaria aspectos mais lúdicos e com requintes de arte. Neste particular, a força do senso comum ou da doxa, na visão de uma hermenêutica de profundidade (THOMPSON, 2000) assume um lugar de prestígio, não menos importante do que outros elementos do processo de análise que a hermenêutica de profundidade sugere.

Há por certo quem possa estranhar o que pode desde o início parecer um acúmulo desnecessário de entradas de tipo metodológico ao universo do objeto de estudo em questão. Também haverá quem queira criticar a sensação de falta de rigor na aplicação do método que, a nosso juízo, a visada compreensiva e a escolha do gênero do ensaio possibilitam, no sentido principalmente de uma proposta de tipo conversacional. E, aí, como pensamos, todo estranhamento e toda crítica precisam de um palco para sua apresentação e de ouvidos atentos para o gesto, sem garantias de sucesso, do diálogo e da compreensão.

Dito isso, convém, no entanto, observar que o recurso à análise de conteúdo deve ser entendido como parte integrante do eixo principal da abordagem metodológica, a hermenêutica de profundidade, como esboçada por John B. Thompson, em Ideologia $e$ 
cultura moderna (THOMPSON, 2000), a serviço do labor interpretativo. Nesse sentido, a hermenêutica de profundidade permite, sugere e promove o uso de distintas metodologias. Semelhante observação pode ser feita em referência ao método da compreensão, que, aqui, assume em boa medida um estatuto de meta+odós como caminho do espírito, como vem sendo indicado e como pretendemos que vá se tornando mais claro na continuidade.

0 esforço hermenêutico mais robusto de Thompson tem em mira o tema da ideologia, uma questão que, não sendo de forma alguma ignorada, ou, pior, negada por nós neste texto, acaba por ser apenas tangenciada, embora atravesse desde as primeiras linhas os sentidos mobilizados pela análise. Com o seu método, seguindo os caminhos de pensadores e hermeneutas como Martin Heidegger e Paul Ricoeur, Thompson (2000) dá um passo à frente, em direção a um aprofundamento do ato interpretativo. 0 ponto de partida é, segundo a proposta do autor, a vida cotidiana, sendo tarefa inicial o que ele chama de análise da doxa.

Essa hermenêutica da vida cotidiana - ou o "fio de Ariadne do senso comum", como expressa Hannah Arendt (2008) em sua cruzada em defesa do gesto intelectual da compreensão -, isto é, esse momento hermenêutico primeiro, constitui um elemento essencial, e, portanto, imprescindível, do processo de interpretação e reinterpretação proposto por Thompson. Essa primeira e basilar abordagem do tema cuida de perceber como o fenômeno da produção de sentidos - e de ideologias, na perspectiva thompsoniana se apresenta, a partir da observação do senso comum e das ideias, princípios e valores que circulam no tecido social.

Feita a interpretação possível da doxa, são três os momentos seguintes da hermenêutica de profundidade, sempre de acordo com esse autor na obra indicada, a saber: análise sócio-histórica, análise formal ou discursiva e a interpretação/reinterpretação. Na prática, os distintos momentos da aplicação da metodologia, aqui como na obra de Thompson separados apenas para efeito de clareza na exposição dos conteúdos, imbricamse, se misturam, dialogam entre si, se aproximam e às vezes se afastam, se fertilizam. Também por uma questão de espaço, neste nosso ensaio, que por mais de uma razão os nossos interlocutores podem considerar convoluto, nem daria mesmo para indicar o passo a passo do how to do do método. Contentamo-nos nesse campo com a indicação de elementos desse esforço e com o apontamento de possibilidades hermenêuticas. 
Por análise sócio-histórica entendemos desde aquilo que dissemos sobre a Nike, enquanto corporação e suas estratégias de marketing e publicidade associadas ao futebol, quanto uma apresentação das condições sociais, políticas e econômicas no interior das quais essas peças foram produzidas. 0 Brasil de 2006 (primeiro governo Lula), quando da Copa na Alemanha, nem de longe era o país que, em 2018 (Copa da Rússia), terá passado por distintas crises políticas, culminando no impeachment da presidente Dilma Rousseff. Os desdobramentos dessa crise desembocariam, no final de 2018, na eleição de Jair Bolsonaro. Reconhecida e assumidamente de direita, o mandatário que assume o poder parece que a cada novo dia sente maior prazer em promover fortes ameaças de cunho autoritário contra a jovem democracia que três Copas do Mundo antes acabara de se implantar no País, após vinte anos dos tempos sombrios (ARENDT, 2008) da Ditadura Militar.

No âmbito da análise formal ou discursiva, o segundo passo do método, depois do empenho analítico preliminar da doxa, concentramo-nos fundamentalmente no estudo, análise e descrição das quatro peças publicitárias que formam o corpus da pesquisa - e, neste ensaio, de uma das peças publicitárias, o comercial Mandingas (2010). Esse momento, como avisamos, serve-se de uma metodologia já consagrada na pesquisa científica na área das Ciências Sociais e Humanas, a análise de conteúdo, no sentido da obra Análise de conteúdo, lançada originalmente na França, no final dos anos 1970, e que chegou até nós como resultado, também, das peripécias vivenciadas pelo método no período, reveladoras tanto de suas virtualidades quanto de seus limites (BARDIN, 2011). Entendemos que as três categorias de análise eleitas para este estudo - Religiosidade, Jornada do Herói e Identidade Nacional - podem dar conta dos principais sentidos construídos pela Nike para celebrar o "país do futebol", no sentido do que poderíamos chamar de uma poética do imaginário.

Por fim, alcança-se o momento hermenêutico propriamente dito, da interpretação/reinterpretação, que se associa e avança em relação à proposta hermenêutica da análise de conteúdo, como corolário dos distintos olhares lançados sobre o objeto de estudo, a partir do embate com o cotidiano, as condições sócio-históricas e a análise formal ou discursiva - uma condição que a Hermenêutica de Profundidade não apenas permite, mas praticamente exige, num esforço multiangular e multiperspectívico, cujo objetivo principal é, então, o de permitir uma hermenêutica de tipo aprofundado. Isso se dá, no trabalho, cruzando-se e entrecruzando-se dados e descobertas, buscando iluminação nos 
referenciais teóricos, apropriando-se de elementos provenientes tanto da parte narrativodescritiva quanto documental, pondo em prática o método maior da reflexão, do argumento e da própria hermenêutica.

Veronese e Guareschi (2006), escrevendo sobre a hermenêutica de profundidade como ferramenta consagrada na pesquisa em Ciências Sociais, chamam a atenção para um dado de enorme relevância, para nós, neste trabalho: o distanciamento em relação a um racionalismo tout court e o trabalho por "aproximações", no melhor sentido de uma hermenêutica. Esse ponto de vista nos posiciona favoravelmente em relação à mirada compreensiva, que, entre outras intuições que cultiva, propõe o ensaio como gênero (não melhor, nem único) preferencial de escrita, por sua aderência maior à ideia de conversa e, em casos bem-sucedidos, de diálogo sobre os objetos e questões de pesquisa. Somam-se a isso, na opção pela hermenêutica e pelo gênero do ensaio, a renúncia voluntária e esclarecida a uma ideia monocrática de razão, verdade e certeza, que, na pesquisa, acaba por ser responsável por enormes mutilações do espírito e das práticas cotidianas, sociais e políticas.

Operando no tom da conversa e de um conhecimento que, não se arrogando o estatuto de uma verdade universal e absoluta, se propõe a dialogar com as incertezas e complementaridades entre opostos, o método da compreensão se contenta muitas vezes com o aprender que vem do caminho percorrido (meta+hodós) e com a propositura de um conhecimento pertinente. Trabalha no nível da compreensão mais que no da explicação sobretudo, não faz do que costumamos chamar de signo da explicação, essa espécie de rolocompressor violento e arrogante em seus contornos mais antidemocráticos, uma meta. Prefere o talvez ao portanto, a noção dialógica ao conceito fechado, que constrói cercas e muros onde uma razão dialógica pode com maior proveito para o espírito entender que vale mais a pena trabalhar com vírgulas, reticências e interrogações que com pontos finais (KÜNSCH, 2020). Desnecessário seria frisar, mas o fazemos em favor de nosso argumento, como os estudos do imaginário, como atestam Barros (2015) e Barros e De Carli (2019), conversam melhor e mais fertilmente com a compreensão que com a explicação, nos sentidos por nós expostos. 


\section{0 comercial 'Mandingas'}

A escolha do comercial Mandingas (2010), com 6' e 20" de duração, desenvolvido pela agência F/Nazca Saatchi \& Saatchi e exibido na rede Cinemark, para promover a camisa azul da Seleção Brasileira de Futebol, pouco antes da Copa do Mundo de 2010, nos ajuda a compreender os distintos momentos de aplicação de nossa proposta metodologia e alguns dos resultados trazidos nas Considerações Finais.

O filme abre com o jogador Robinho dando um testemunho. Só então, ao fundo, ouve-se a entrada de um samba, com levada tipicamente africana, e a imagem é então ocupada pela cena de uma fábrica onde se confeccionam amuletos da sorte. Nesse momento, entra um gerador de caracteres com a frase "Nike futebol.com apresenta...". A complementação viria só com quase um minuto e meio de comercial: Mandingas (MANDINGAS, 2010).

O cenário da introdução apresenta uma feira popular em que aparecem amuletos religiosos (colares de miçangas, figas, carrancas, folheto de "São Longuinho" e outros). Uma senhora negra adquire uma figa, que é levada a um pequeno oratório em que aparecem velas de várias cores e tamanhos, imagens de Nossa Senhora Aparecida, São Jorge, amuletos variados, numa imagem plástica do sincretismo religioso que aparece nos estudos (CUNHA, 2007) como uma das marcas da vivência religiosa do brasileiro. Sobre essas imagens, a voz do rapper Thaíde, que é o narrador em off de todos os textos da peça, canta um samba.

É... / é da hora o baguio... / Sorte, talismã, mandinga, habilidade, arte, ginga, destino, competição, bola no pé, intuição. É ou não é? / É a crença... é a nossa crença. / Às vezes até parece que é até por isso que a barriga em que a gente vive antes de nascer é redonda. / É isso mesmo. / Certo? / Isso a gente tem de bastante. / É isso mesmo. / Certo? / "Vamo que vamo"... / Sou brasileiro. / É pura mandinga. (MANDINGA 2010).

Na sequência, o comercial se divide em quatro quadros. 0 primeiro ato tem como personagem central o manto de Nossa Senhora Aparecida. Uma narração em off sobre uma série de imagens que aparecem na seguinte sequência: cenas da Copa do Mundo da Suécia (1958) em preto e branco; ilustrações coloridas de figas; um filme mostrando a camisa azul com o número sendo costurado manualmente; uma pequena animação - visualmente 
remetendo à literatura de cordel -, ilustrando como se deu a comunicação aos jogadores de que a Seleção Brasileira jogaria de azul até a consagração como campeões mundiais; a camisa azul aparece em close, e voltam as cenas dos amuletos e mandingas da sorte. 0 off acompanha as imagens, reforçando os aspectos de superstição/fé/mandinga ali presentes, e reproduzindo um suposto diálogo em que o chefe da delegação brasileira na ocasião anuncia aos jogadores que o Brasil jogaria a final de camisas azuis porque esta era a cor do manto de Nossa Senhora.

Figura 2 - Ilustração de avião levando a Seleção Brasileira e a sua fé para o Mundial da Suécia, em 1958

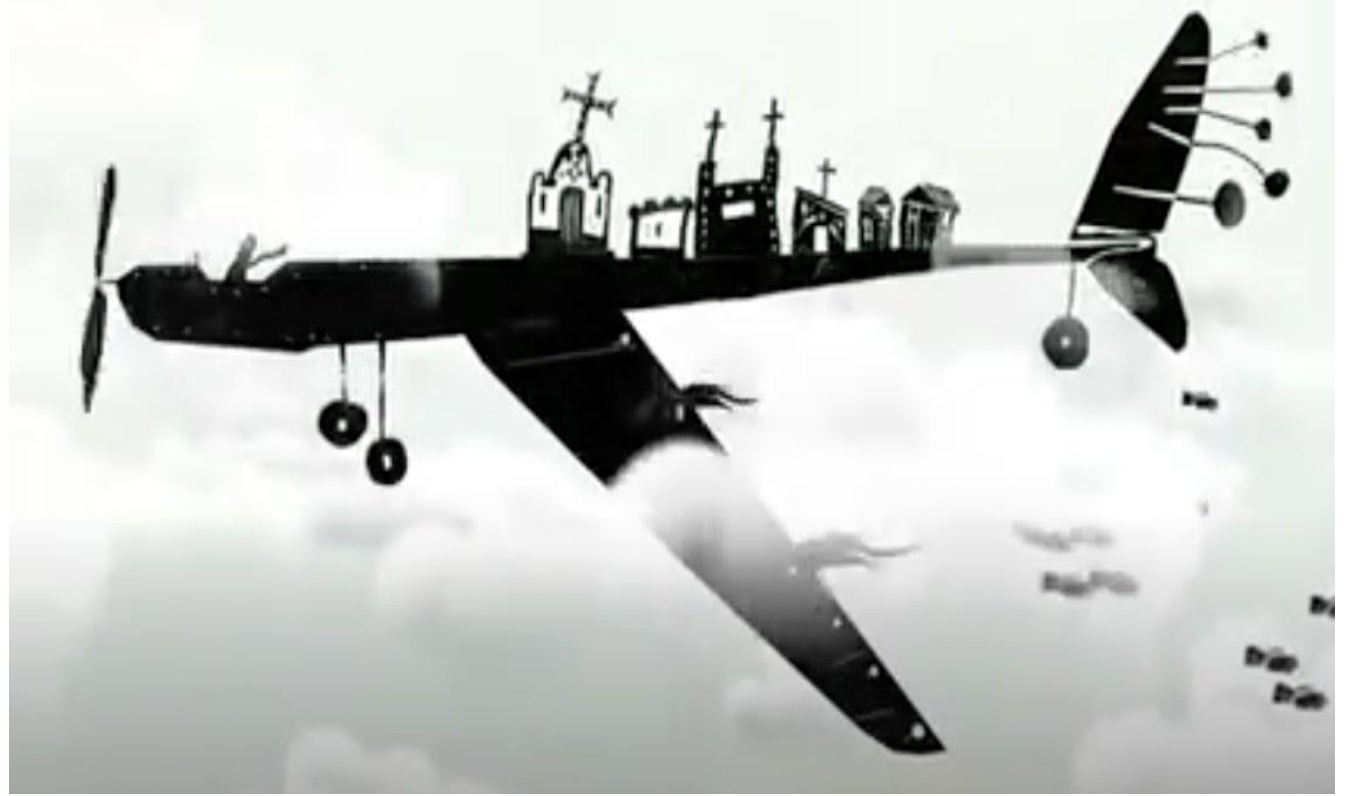

Fonte: Mandinga (2010, [Frame 2'03"]).

O personagem do segundo ato é o jogador Maicon, da Seleção de 2010. As imagens o apresentam inicialmente com o uniforme azul, sob vários ângulos, depois dividindo a tela com o texto "A peça chave pelo lado direito". Na sequência, o símbolo da Nike aparece rapidamente, enquanto uma animação ilustra a história narrada pelo jogador, também em linguagem visual próxima ao cordel. E, para finalizar, o jogador conta que o pai enterrou o seu cordão umbilical (e o do seu irmão gêmeo) em um campo de futebol, pedindo a Deus para que o filho se tornasse um dia jogador. A locução alterna off sobre uma animação e o testemunho do jogador em close. 
Figura 3 - Apresentação do jogador Maicon, da Seleção Brasileira de 2010 (os demais são apresentados de forma similar)

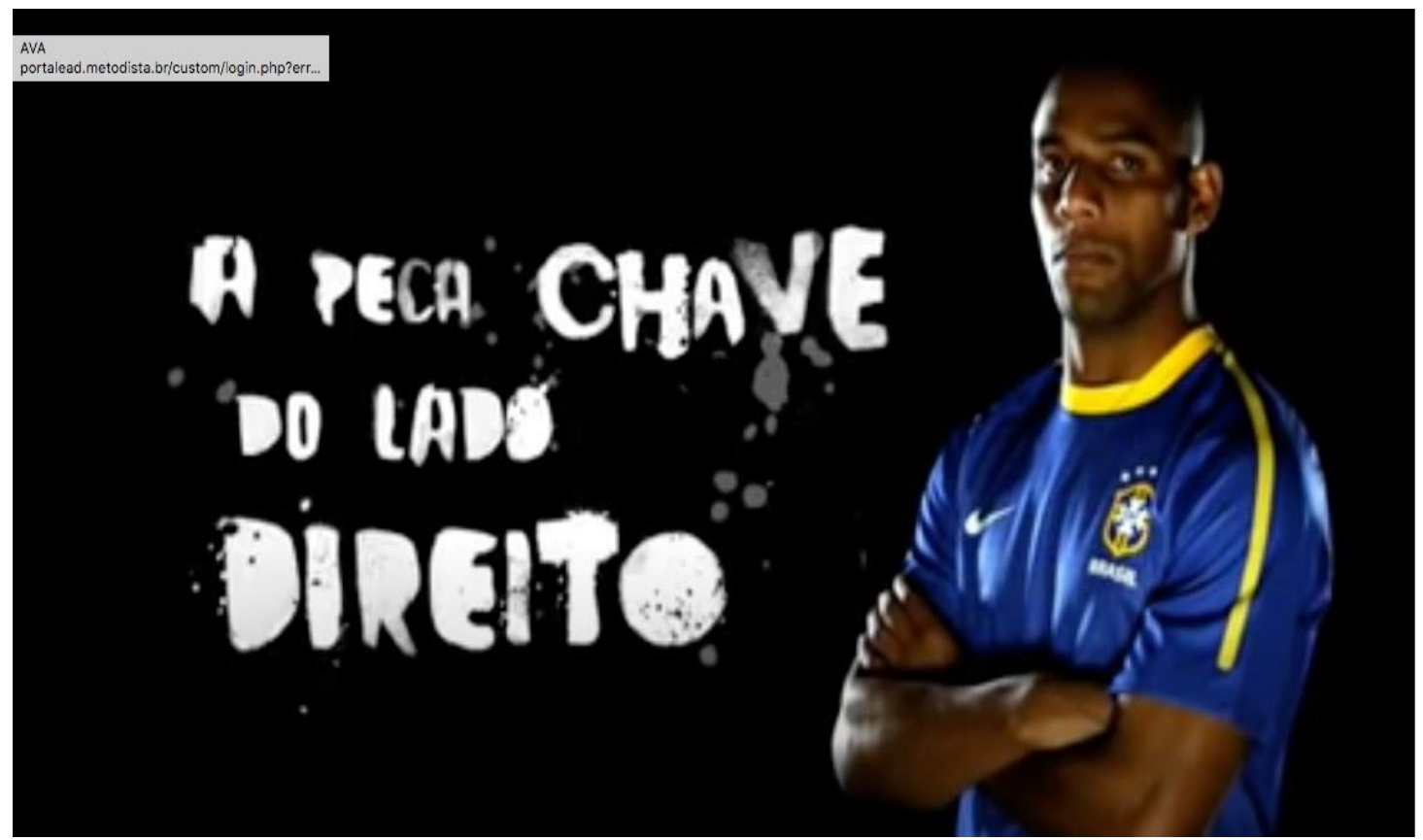

Fonte: Mandinga (2010[Frame 2'53"]).

O jogador Robinho domina o terceiro ato, sendo apresentado como "O homem de confiança do Professor". Mais uma vez teremos locução, testemunho do jogador e animação de tipo cordel. O locutor começa: “O avô de Róbson de Souza, o Robinho, era um pai de santo bem conhecido na região. Assim que a nora engravidou, preste atenção no detalhe, ele fez um trabalho forte para que o menino fosse menino, menino e jogador de futebol". Depois é o jogador quem assume a narrativa, enfatizando que o avô aparecia constantemente para dizer à sua mãe, ainda grávida, que o menino que ela carregava na barriga seria jogador de futebol.

Luís Fabiano, o terceiro jogador, fecha a série de quatro quadros. 0 roteiro de apresentação é o mesmo. Closes na camisa azul, no logotipo da Nike, no jogador sob vários ângulos, e a frase: "O dono da 9 mais desejada do mundo". Neste esquete, a animação em cordel é substituída por um vídeo. 0 narrador faz uma introdução, que é seguida pelo testemunho do jogador em que ele conta que um suposto pai-de-santo apareceu um dia no campinho em que ele jogava uma pelada quando criança e, apontando de um em um, revelou que ele iria se tornar um jogador de futebol. Em seguida, segundo o jogador, o suposto anjo/pai-de-santo desaparece. "Beleza, né? Voltamos a jogar e ele sumiu. Sumiu! 
Ninguém viu ele saindo..., ninguém..., desapareceu. E eu acho que ele era um anjo ali que... enviado para dizer que eu iria virar um jogador. E hoje eu tô aí, Luís Fabuloso. Virou o Fabuloso."

Figura 4 - 0 jogador Luís Fabiano recebe a visita de um enviado misterioso para dizer que ele seria um jogador de futebol

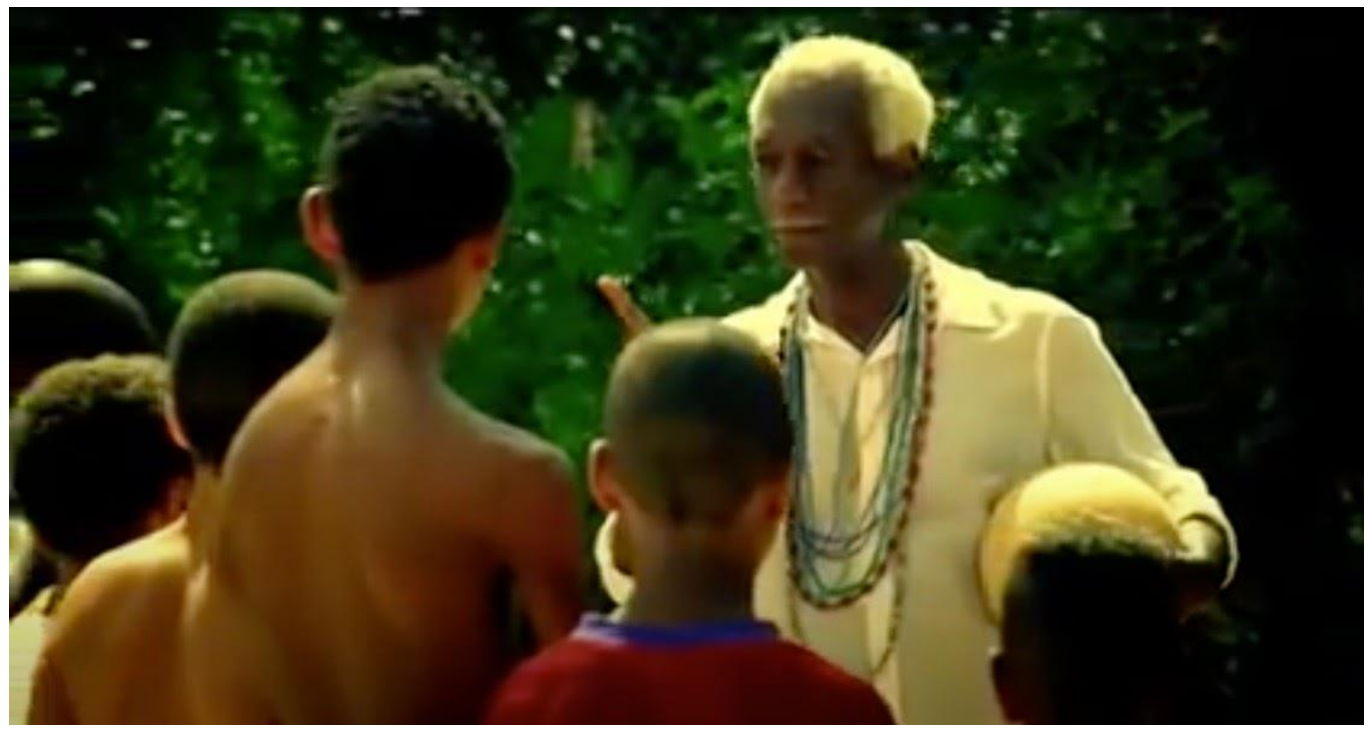

Fonte: Mandinga (2010, [Frame 4'40”]).

Para finalizar, há uma cena em que Luís Fabiano canta um rap, aparentemente de improviso, como se fosse um making of, descrevendo a sua trajetória desde o tempo dos campinhos de terra na periferia da cidade de Campinas, no interior de São Paulo.

Em nosso caminho hermenêutico, e seguindo a sugestão de Thompson, partimos, pois, da interpretação da doxa, ou seja, "uma interpretação das opiniões, crenças e compreensões que são sustentadas e partilhadas pelas pessoas que constituem o mundo social" (THOMPSON, 2000, p. 364). Observamos o papel fundamental dos personagens do cotidiano como mediadores dos conteúdos do imaginário. E também, como produtores e reprodutores de antigos e novos sentidos a partir das interações com os símbolos e os entendimentos que circulam pelo ambiente social em que os consumidores da Nike, e os brasileiros, estão inseridos.

É nessa fase inicial da análise que nos apoiamos aqui, com maior afinco, reservando para as Considerações Finais alguns dos resultados que emergem da aplicação do conjunto de fases da hermenêutica de profundidade, com o apoio da análise de conteúdo e sob a luz 
do método da compreensão. Situamo-nos, pois, com essa análise primeira, no universo dos sentidos que sedimentam e atravessam o mundo social sobre o Brasil imaginado, elementos simbólicos dos quais a publicidade se alimenta e com os quais interage, e cujos significados dão sentido à própria criação publicitária. Por consequência, mediante o alcance e a penetração dos anúncios, o uso desses elementos, fortemente arraigados no senso comum, faz da própria publicidade uma mediadora e produtora de novos entendimentos, novas interpretações, novas construções simbólicas.

Mais ou menos evidenciados, certos estereótipos se fazem presentes nas quatro peças publicitárias, a começar por uma ideia que une todas elas: a de um futebol genuinamente brasileiro e, só por isso, mais artístico do que aquele praticado em qualquer outro canto do planeta. Se isso é escancarado no título do comercial de 2006, Joga Bonito nos demais comerciais se apresenta como um recurso veiculado em imagens que prezam por "demonstrar" - entre aspas - que a habilidade e a arte são inerentes ao brasileiro. Uma das formas de representar essa suposta diferença é utilizada em todas as peças a partir de 2010: o futebol de rua, a pelada e o campinho de terra, a comunidade periférica, o barraco... Esses elementos assumem no contexto a função (ideológica?) de tentar, pela via da carência de recursos e da pobreza, aproximar a prática do esporte a todos os brasileiros, como que assinalando que a arte não é uma ferramenta apenas de profissionais.

O chamado estilo brasileiro de jogar futebol é, sem dúvida, uma crença partilhada e sustentada socialmente, e, portanto, um elemento da doxa. Somos dotados de um estilo próprio, superior, também porque possuímos um gingado particular, uma capacidade de improviso exclusiva e uma malandragem, entendida nesse caso de forma positiva, que nos acompanha e que poderia ser lida como uma manifestação de criatividade - quase sempre usada para nos safar de problemas. Essas três supostas características "do brasileiro" participam do imaginário social, inclusive, para além dos campos de futebol, de forma que, neste caso, temos percepções complementares que se (retro)alimentam mutuamente. E, mutatis mutandis, nos entendemos malandros, com gingado e capacidade de improvisar, porque temos um estilo brasileiro, e só nosso, de jogar futebol.

Ao estilo brasileiro de jogar futebol se soma um entendimento bastante particular de fé. É a fé do brasileiro que, em primeiro e importante lugar, possui marcas de sincretismo religioso. Deuses, santos, superstições e figuras religiosas de diversas matrizes convivem em 
harmonia no entendimento do Sobrenatural. 0 cristão europeu ocidental, o indígena, o africano e outras matrizes religiosas se mesclam e negociam sentidos num universo real e imaginário em que se destacam os elementos africano e cristão, materializados de alguma forma na história do manto de Nossa Senhora Aparecida.

No entanto, para além do sincretismo, há o entendimento das relações particulares entre o brasileiro e esse Sobrenatural. O Ser Superior da fé do brasileiro, sempre dentro do arco de sentidos dessa forma de imaginar o imaginário, é prático e sempre pronto a interferir a nosso favor, uma vez que o brasileiro carrega algum tipo de predestinação como forma de compensar as dificuldades sociais e econômicas da vida real (uma alusão ao ensinamento cristão de sofrer aqui para gozar depois da morte da bem-aventurança do Paraíso Celeste?). 0 brasileiro de fé deposita as suas esperanças na intervenção divina, especialmente, porque tem com o seu jeito e o seu destino uma espécie de canal direto com Deus, para quem o brasileiro apresenta os seus pedidos, dito de forma geral, sem precisar de instituições ou de autoridades religiosas como mediadoras.

Dessa forma, a fé que permeia a sociedade não pertence a nenhum código escrito, não segue nenhuma regra, nem obedece a nenhuma lógica, a não ser a lógica ilógica da própria crença, sustentada e partilhada pela sociedade e cuja interpretação depende de um contrato estabelecido no imaginário social do brasileiro. Se temos estilo brasileiro de jogar futebol, também podemos dizer que temos o estilo brasileiro de fé. Mandingas (2010) é, antes de mais nada, uma apresentação de todas essas nuances religiosas onde a publicidade, de ordinário, busca elementos de pertencimento e de estabelecimento de vínculos. Esse entendimento de religiosidade, como avançado, pode ser visualizado também nas demais peças analisadas, ainda que não com tamanho destaque e protagonismo, como em Mandingas.

Na linha de que existe uma forma de perceber a brasilidade formada no imaginário do próprio brasileiro, um outro elemento simbólico se faz presente em três dos quatro filmes analisados: o muito sério problema habitacional que atinge faixas gigantescas da população nacional, representado em imagens de favelas, moradias precárias, becos ou cenários urbanos degradados, esgoto a céu aberto. Essas imagens aparecem com maior discrição em Mandingas, ainda que seja importante destacar que, na narrativa do jogador Maicon, a cidade de Criciúma, em Santa Catarina, de colonização predominantemente alemã, 
aparece tendo ao fundo um morro e um barraco no topo. Essas imagens se fazem levemente mais presentes em Mostra o seu jogo (2014), que intercala cenas do cotidiano na periferia com imagens de cartão-postal do Rio de Janeiro. E explodem em Brasileiragem (2018), um comercial quase por completo ambientado em quadras, campinhos de terra, becos e vielas que remetem à periferia e às comunidades mais pobres.

Mais uma vez, o que temos é uma construção simbólica, sobretudo em Brasileiragem (2018), que sugere idilicamente que o brasileiro se conecta de forma emocional e se identifica com a ideia de que a melhor representação da sua identidade esteja na periferia. 0 brasileiro de verdade, no caso, não é o da Avenida Faria Lima em São Paulo, nem o da Avenida Vieira Souto no Rio de Janeiro, muito menos o de Brasília. No melhor estilo de sacramentalização da miséria, o que o imaginário reconhece é a vida do subúrbio, da moradia precária, do lazer das peladas em espaços públicos; é o ambiente do boteco e da cachaça, da roda de samba no bar da esquina...

No caso da música, não interessa se de tipo-exportação (como em Joga Bonito), um batuque de matriz africana e uma levada de samba (Mandingas), uma exaltação patriótica com pitadas de rap (Mostra o seu jogo) ou um hip-hop ao estilo brasileiro (Brasileiragem), o que se percebe é que todas elas podem ser compreendidas como manifestações musicais, digamos assim, genuinamente brasileiras. A diferença entre elas é mais justificada pelo contexto social e histórico de produção dos filmes do que por questões de estilo musical.

E, finalmente, a negritude. A importância do negro para a popularização do futebol está na raiz desse esporte no Brasil conforme bem retrata Mário Filho na obra $O$ negro no futebol brasileiro (2003), ao expor que os negros eram deslocados para funções menos desgastantes nas fábricas - vale lembrar que o futebol era amador e os times eram formados nas fábricas, principalmente, de origem inglesa -, para terem melhores condições físicas para jogar futebol. Se o jogador negro, vindo da periferia e das funções menos nobres nas fábricas, conquistou algum espaço social por meio do futebol no início do século XX, o fato é que as condições da população de baixa renda, onde predominam pretos e pardos, ainda fazem do futebol uma porta de entrada para uma vida melhor, ou uma esperança possível. Some-se a isso outro aspecto indiscutível: a grande maioria dos jogadores brasileiros de sucesso, ao longo da história, eram negros ou pardos, e não vinham de famílias abastadas. Pronto, não fica difícil entender que é negro que o brasileiro comum se enxerga; é na 
população negra e parda que a representação do que é ser brasileiro se faz presente. Recorrendo a Caetano Veloso, na música Haiti, "pretos, pobres e mulatos, e quase brancos quase pretos de tão pobres" (HAITI, 1993), são a essência do que se entende por futebol brasileiro, até porque estes são os principais expoentes do jeito brasileiro de jogar futebol.

É nesse caldeirão de representações que se constrói uma identidade nacional, sustentada por outras representações simbólicas que compõem, alimentam e realimentam "uma interpretação das opiniões, crenças e compreensões que são sustentadas e partilhadas pelas pessoas que constituem o mundo social" (THOMPSON, 2000, p. 364). E como parte da análise sócio-histórica, que neste ponto do nosso texto podemos apenas levemente esboçar, Thompson entende todo o contexto em que os símbolos são produzidos, transmitidos e absorvidos. Um dos passos é compreender que as mensagens circulam em momentos diferentes, para pessoas que se encontram em ambientes diferentes, possibilitando a análise daquilo que é comunicado e entendido, a que o autor dá o nome de "análise sociotemporal".

Com Mandingas (2010), a Nike produz um filme comercial olhando para o mercado interno. Se o cenário político, econômico e social em 2006 era positivo, em 2010 as coisas pareciam ainda melhores, com o Brasil assumindo o seu papel de potência global emergente e a inserção de milhões de brasileiros no universo do consumo. No que diz respeito à negritude, uma interpretação possível é que a utilização de personagens exclusivamente negros (incluindo o locutor, o rapper Thaíde) se traduz numa intenção deliberada de gerar identificação com a classe $C$, em que predominam negros e pardos, com suas novas possibilidades de consumo, inclusive de produtos mais sofisticados como pode ser a própria camisa oficial da Seleção Brasileira. De outro lado, é possível entender como essa ascensão social frequentou, quase que de forma natural, o imaginário do publicitário, visto como sujeito inserido em um determinado tempo histórico e social, de forma que a criação e a roteirização caminharam como que involuntariamente nessa direção. Estando provavelmente a virtude da interpretação no meio, é possível também imaginar que motivos conscientes e inconscientes se cruzam nessa empreitada, para além das estratégias racionais do marketing e da promoção do consumo. 


\section{Alguns resultados alcançados}

Sem um ponto determinado por onde a conversa tenha necessariamente que iniciar - para além dos protocolos básicos da produção científica -, o esforço ensaístico também não se vincula a uma obrigação de chegar a conclusões que se vejam como definitivas. Nem muito menos a estabelecer pontos finais para uma conversa que mais abre flancos e levanta questões, inclusive críticas, que apontam na direção de novas interrogantes. Assim, o encerramento, no caso de um ensaio, está longe de significar que a conversa tenha que ter acabado.

O dualismo ontológico, epistemológico e também metodológico que trabalha o tempo todo com a noção de certo e errado, luz e escuridão, Deus e o Diabo, como opostos, é incapaz de dialogar com uma atitude intelectual compreensiva e com o melhor que o gênero de escrita do ensaio se propõe a oferecer. Princípios tão importantes como o da incerteza e o da complementaridade dos opostos poderiam aqui ser invocados.

Os mais fervorosos gritarão em defesa do rigor. Podem com isso estar se revelando incapazes de negociar com a ideia de um mundo "misturado", na expressão do personagem Riobaldo em Grande sertão: veredas, de Guimarães Rosa (2019). Podem com isso, também, estar se revelando incapazes de entender que o acento mais ou menos dogmático sobre a ideia de verdade não raramente serve apenas para nos apaziguar e nos iludir frente à arte difícil de negociar com nossos erros e com nossas sombras.

A pesquisa de doutoramento de um dos autores que serve como plataforma teórica e analítica ampla para a construção deste ensaio mostra que a Nike vincula a sua estratégia de comunicação, no Brasil, fundamentalmente, a questões de identidade cultural. É diferente, por exemplo, de países como os Estados Unidos e a Rússia, onde essa comunicação assume um caráter marcadamente político-social.

Considerando que essa comunicação, no Brasil, se conecta a aspectos do imaginário social, concentramo-nos, na pesquisa sobre o tema, no estudo e análise das quatro peças publicitárias da Nike para as Copas do Mundo de Futebol de 2010 a 2018, com destaque para o comercial Mandingas, produzido para a Copa do Mundo de 2010, na África do Sul. Para tanto, nos servimos da ferramenta da hermenêutica de profundidade, com o suporte especial da análise de conteúdo em uma de suas fases. Os distintos momentos da aplicação da metodologia nos remetem de novo ao trabalho original de onde este ensaio emerge, o 
que poderia inclusive ser apontado como um limite por parte daqueles que se acham no justo direito de perguntar por que deve ser assim e não de outro modo. Porque, aqui, de fato, como nos parece que possa ser dito, a metodologia aparece antes indicada e explicitada em seus propósitos do que aplicada em suas múltiplas possibilidades, concreta e exemplarmente. Talvez se pudesse argumentar, a nosso favor, que o meta+odós não precise necessariamente ser visto e apreciado apenas em suas relações com os resultados que nos permite alcançar em nossas pesquisas. 0 meta+odós não deixa de assumir igualmente um estatuto epistêmico no próprio fato de ser apontado, visto e apreciado como um caminho possível, entre outros.

Este estudo, tanto nesta sua versão de ensaio quanto da pesquisa doutoral que lhe serviu de base, está longe de alimentar a doce ilusão de pretender aprofundar o mais possível, e muito menos de esgotar as questões relacionadas à cultura que podem ser levantadas a partir do tratamento das peças publicitárias analisadas. Por um lado, porque o próprio entendimento de cultura é amplo demais para que se tente defini-lo. Depois, porque o trabalho de interpretação dos muitos significados não é estático, mas condicionado tanto pelo imaginário, que se desloca constantemente, quanto pelo contexto sócio-histórico em que a mensagem é produzida, absorvida, negociada, reproduzida. Dessa forma, os resultados da pesquisa admitem a convivência com a ideia de um vigor dialógico, propondo que questões em aberto conversem com outras pesquisas, no estilo do método da compreensão em que se inspira.

Isso posto, e tendo sobretudo como ponto de partida o estudo de Mandingas (2010), é possível avançar alguns dos resultados alcançados. Em primeiro lugar, ainda que se considere a reconhecida qualidade de produção - e quando falamos da Nike, obviamente, os investimentos são proporcionais à grandeza da marca -, o comercial entrega a sensação de que a narrativa faz sentido, que ela constrói uma ordem (possível) de sentidos no arranjo social. Mais que isso, quando analisado à luz do contexto sócio-histórico, Mandingas, como poderíamos dizer, faz ainda mais sentido. Nada mais adequado, nos parece, do que heróis pretos e pardos, com histórias de superação, para ir ao encontro do momento de emergência dos mais pobres que se vivia no Brasil naquele período.

Não podemos descartar que a campanha faça sentido, primeiro, para a equipe de publicitários que a desenvolveu (a bem da verdade, para a criação de campanhas deste 
porte, uma equipe multidisciplinar é envolvida, incluindo um corpo maior ou menor de pesquisadores de distintas áreas). Embora toda peça publicitária parta do princípio de que ela tem que fazer sentido para uma audiência de modo a influenciá-la, os publicitários também são audiência, e a narrativa, por isso, se sente como que na obrigação de fazer sentido em primeiro lugar para eles. Assim, eles influenciam e são influenciados. E tal fenômeno se estende por todo público, de uma forma que, por um lado, leva à construção de sentidos na audiência e, por outro, reafirma estes entendimentos que realimentam o imaginário social (onde os publicitários encontram a sua fonte), num processo constante e dinâmico de produção e de reprodução de sentidos.

Mandingas (2010) inicia um processo, que se mantém nos anos seguintes, de aproximação de tipo cultural entre a Nike e o Brasil. Dentre os maiores mercados da empresa, como se pode extrair mais uma vez da pesquisa realizada, esta estratégia, que poderia num certo sentido ser vista como relativamente despolitizada, se revela como única. Isso se deixa mostrar de modo particularmente forte no caso da abordagem mítico-religiosa, caracterizada por elementos do imaginário religioso brasileiro, que inclui modos de entendimento da religião e práticas rituais características, como descritas pela Matriz Religiosa Brasileira, na formulação de Magali Cunha. Fé em Deus e mobilidade social se unem nessa tarefa de preencher o imaginário e criar conexões emocionais que geram uma percepção comercial da marca, para além dos múltiplos significados materiais de seus produtos. A categoria da Religiosidade foi uma das nossas escolhidas para esta análise, e se mostrou amplamente pertinente no confronto com o comercial Mandingas. Aliás, uma breve incursão pelo imaginário religioso nacional pode nos revelar o quanto o próprio termo "mandingas" tem a revelar sobre o comércio do brasileiro com o Sobrenatural.

Semelhantes aproximações podem ser tecidas com as duas outras categorias de análise, a da Identidade e a da Trajetória do Herói. Fixamo-nos, para tanto, e isso também pode ser cobrado de nós como um limite analítico, de modo bastante incisivo nos domínios da doxa e do senso comum. Pode ser cobrado, sim. Mas longe de nós fazer desse mundo vivido o lugar da ignorância e do desprezo, uma ideia bastante macabra, e epistemologicamente torpe, que uma certa visão positivista insiste em cultivar como valor. Sem nunca desprezar os distintos níveis possíveis de análise e o refinamento também 
possível de todo ato interpretativo, convém porém insistir que o mundo da vida tem como suporte de seus pensares e fazeres a ideia de que primum vivere, deinde philosophari.

Em um ponto, parando por aqui, tanto o fundador da Nike, Phil Knight, quanto os apoiadores e também os críticos da corporação e do modelo de negócios que a empresa assume, parece que podem estar de acordo: que a marca Nike constitui o primeiro e principal negócio da própria Nike. Um negócio dos deuses. Ou da deusa Niké. Em função desse objetivo maior é que a marca dialoga a seu modo com o imaginário do brasileiro - ou com o Brasil imaginado -, de forma a criar vínculos emocionais com esse público e transformar os seus produtos em objeto do mais puro desejo. Esse saber-fazer, como nos parece ter de algum modo deixado claro, não pode não ser reconhecido.

\section{Referências}

ARENDT, Hannah. Compreensão e política (As dificuldades da compreensão). In: Compreender: formação, exílio e totalitarismo. São Paulo: Companhia das Letras; Belo Horizonte: Editora da UFMG, 2008, p. 330-346.

BARDIN, Laurence. Análise de conteúdo. São Paulo: Edições 70, 2011.

BARROS, Ana Taís Martins Portanova. Caderno de resumos do II Congresso Internacional do Centre de Recherches Internationales sur l'Imaginaire - A teoria geral do imaginário 50 anos depois: conceitos, noções, metáforas. Porto Alegre: Imaginalis, 2015.

BARROS, Ana Taís Martins Portanova; DE CARLI, Anelise Angeli (Orgs.). Comunicação e imaginário no Brasil: contribuições do grupo Imaginalis (2008-2019). Porto Alegre: Imaginalis, 2019.

BAUMAN, Zygmunt. Modernidade líquida. São Paulo: Zahar, 2001.

BRASILEIRAGEM. Locução de: Fabio Brazza (Fabio Rebouças de Azeredo). Brasil, 2017. 1 vídeo (60 seg). Publicado pelo canal Nike Futebol. Disponível em: https://youtu.be/iV1T5hWzXW0. Acesso em: 17 out. 2020.

CAMPBELL, Joseph. 0 herói de mil faces. São Paulo: Pensamento, 1989.

CANCLINI. Néstor Garcia. Culturas híbridas: estratégias para entrar e sair da Modernidade. São Paulo: EDUSP, 2000.

CUNHA, Magali do Nascimento. Explosão gospel: um olhar das ciências humanas sobre o cenário evangélico no Brasil. Rio de Janeiro: Mauad, 2007. 
CUNHA, Magali do Nascimento. Crise, esquecimento e memória: o centro ecumênico de informação e a construção da identidade do protestantismo brasileiro. Rio de Janeiro, 1997. Dissertação (Mestrado em Memória Social e Documento). Centro de Ciências Humanas, Universidade do Rio de Janeiro.

DEBORD, Guy. A sociedade do espetáculo. São Paulo: Contraponto, 2007.

FILHO, Mário. 0 negro no futebol brasileiro. 4. ed. Rio de Janeiro: Mauad Editora, 2003.

HAITI. Compositores e intérpretes: Gilberto Gil; Caetano Veloso. In: TROPICÁLIA 2. Compositores e intérpretes: Gilberto Gil; Caetano Veloso. Rio de Janeiro: Gravadora Philips, 1993. 1 CD, faixa 1.

HELAL, Ronaldo. 0 que é Sociologia do Esporte. São Paulo: Editora Brasiliense, 1990.

HUIZINGA, Johan. Homo ludens: o jogo como elemento da cultura. São Paulo: Perspectiva, 2009.

JOGA BONITO. Locução de: Eric Cantona. Brasil, 2006. 1 vídeo (2 min 37 seg). Publicado pelo canal Gangstalatino123. Disponível em: https://www.youtube.com/watch?v=xFp7btucv58. Acesso em: 17 out. 2020.

JUNG, Carl Gustav. Os arquétipos e o inconsciente coletivo. Petrópolis: Vozes, 2001.

JUNG, Carl Gustav (Org.). 0 homem e seus símbolos. 2. ed. Rio de Janeiro: Nova Fronteira, 2008.

KELLNER, Douglas. A cultura da mídia. São Paulo: EDUSC, 2001.

KLEIN, Naomi. Sem logo: a tirania das marcas em um planeta vendido. Rio de Janeiro: Record, 1999.

KÜNSCH, Dimas A. Compreender: indagações sobre o método. São Bernardo do Campo, SP: Editora Metodista, 2020.

MANDINGAS. Locução de: Rapper Thaíde (Altair Gonçalves). Brasil, 2010. 1 vídeo (6 min). Publicado pelo canal Nike Futebol. Disponível em: https: //youtu.be/ipVxkyPpYSs. Acesso em: 17 out. 2020.

MOSTRA SEU JOGO. Locução de: Emicida (Leandro Roque de Oliveira) e Thiaguinho (Thiago André Barbosa). Brasil, 2014. 1 vídeo (1 min 40 seg). Publicado pelo canal Nike Futebol. Disponível em: https://youtu.be/kT0WLVPfBCM. Acesso em: 17 out. 2020.

OLIVEIRA, Fábio Eloi. Nike, futebol e propaganda: A produção publicitária no Brasil em tempo de Copa do Mundo. 2020, 1450 f. Tese (Doutorado em Comunicação Social) Universidade Metodista de São Paulo, São Bernardo do Campo, 2020. 
ROBERTS, Kevin. Lovemarks: o futuro além das marcas. São Paulo: M. Books, 2004.

ROSA, João Guimarães. Grande sertão: veredas. São Paulo: Companhia das Letras, 2019.

ROSENFELD, Anatol. Negro, macumba e futebol. São Paulo: Perspectiva, 1993.

SOUSA, Mauro Araujo de. Epistemologia da compreensão em viés nietzschiano. In: KÜNSCH, Dimas A.; PASSOS, Mateus Yuri; KLAUTAU, Carolina Moura; MACHADO, Patricia S.; FERNANDES, Paulo Emilio; ABIB, Tayane (Orgs.). Pensar com o signo da compreensão. São Bernardo do Campo: Universidade Metodista de São Paulo, 2019, p. 147-161.

THOMPSON, John B. Ideologia e cultura moderna. São Paulo: Vozes, 2000.

VERONESE, Marília Veríssimo; GUARESCHI, Pedrinho Arcides. Hermenêutica de Profundidade na pesquisa social. Ciências Sociais Unisinos, São Leopoldo, v. 42, n. 2, p. 8593, mai./ago. 2006.

\title{
Nike and imagined Brazil: the production of the commercial Mandingas for the World \\ Cup 2010
}

\begin{abstract}
The four advertising for launching Nike campaigns for the World Cups from 2006 to 2018, and particularly the most extensive of them, Mandingas, for the 2010 World Cup, are the subject of this essay, focusing on the imagined Brazil from which this ad production drift. It is intended to show how the largest sporting goods company in the world interacts with the social imaginary, in a double sense, both in the search for its references in that imaginary and, at the same time, in the food and reproduction of these symbolic constructions through the films produced. Methodologically, the research is based on Depth Hermeneutics, as formulated by John B. Thompson, with the support of content analysis and in the broader light of understanding as a method. The text hopes to promote an understanding of how advertising can act as a link between the brand and its audience, which means, in the specific case, with the Brazilian nation itself.
\end{abstract}

\section{Keywords}

Communication; Publicity; Social imaginary; Understanding; Nike 


\section{Autoria para correspondência}

Fabio Eloi de Oliveira

fabio.oliveira@metodista.br

\section{Como citar}

OLIVEIRA, Fabio Eloi de; KÜNSCH, Dimas. A Nike e o Brasil imaginado: A produção do comercial Mandingas para a Copa do Mundo de 2010. Intexto, Porto Alegre, n. 52, e-108576, jan./dez. 2021. DOI:

http://dx.doi.org/10.19132/1807-8583202152.108576

Recebido em 21/10/2020

Aceito em 11/05/2021

(c) $(1)$ (1) 